\title{
ENFOQUE BIOLÓGICO DA CRIMINALIDADE E ORIENTAÇÃO DETERMINISTA: UNILATERALISMO TEÓRICO E POLÍTICA CRIMINAL ANTILIBERAL NO DISCURSO DOS ESTUDIOSOS DA BIOLOGICA CRIMINAL (1930-1960).
}

BIOLOGICAL APPROACH OF CRIMINALITY AND DETERMINING ORIENTATION: THEORETICAL UNILATERALISM AND ANTI-LIBERAL CRIMINAL POLICY IN THE SPEECH OF THE CRIMINAL BIOLOGY SCIENTISTS (19301960).

Ricardo Freitas ${ }^{1}$ Faculdade Damas/PE

Resumo: Este artigo trata do problema do unilateralismo determinista no âmbito da biologia criminal e da política criminal resultante do enfoque biológico com a finalidade de comprovar que, ao contrário do que os estudiosos afirmam frequentemente, a biologia criminal entre as décadas de 1930 e 1960 do século anterior não se caracterizou nem pelo unilateralismo nem pelo determinismo radical, muito embora tenha sugerido a formulação de políticas criminais de natureza antiliberal e, por conseguinte, desfavoráveis aos direitos humanos.

Palavras-chaves

Biologia Criminal. Unilateralismo. Determinismo. Política Criminal.

\section{Abstract}

This article deals with the problem of the unilateral determinism within the scope of the criminal biology and criminal policy as a result of the biological approach with the purpose of proving that, unlike what many scholars often states, criminal

1 Doutor em Direito pela UFPE. Professor do Programa de Pós-graduação da Faculdade Damas da Instrução Cristã. Procurador da Justiça Militar. 
biology between the decades of 1930 and 1960 were not defined neither by the unilateralism nor by the radical determinism, even though it was suggested the development of criminal policy of anti-liberal nature and, therefore, detrimental to the human rights.

Keywords

Criminal Biology. Unilateralism. Determinism. Criminal Policy.

\section{INTRODUÇÃO: PERSPECTIVA BIOLÓGICA UNILATERAL EM CRIMINOLOGIA E POLÍTICA CRIMINAL.}

A criminologia é um saber interdisciplinar, abrigando em seu interior uma pluralidade de saberes particulares. Por esta razão, não existem propriamente profissionais da criminologia, mas médicos, antropólogos, biólogos, sociólogos, psicanalistas e juristas interessados nos múltiplos objetos de pesquisa das disciplinas particulares que a compõem. Uma das vertentes criminológicas é a denominada biologia criminal. Os saberes criminológicos no âmbito da biologia criminal são aqueles que, a exemplo da endocrinologia, da genética, da neurofisiologia, da bioquímica, dentre outros, têm como objeto de estudo "o homem delinquente, tratando de localizar e identificar em alguma parte de seu corpo ou no seu funcionamento, o fator diferencial que explica a conduta delituosa, entendida como consequência de alguma patologia, disfunção ou transtorno orgânico" (GARCÍAPABLOS, 1992:138). Portanto, pode-se dizer que as teorias biológicas da criminalidade baseiam seus conhecimentos acerca da criminalidade no estudo do indivíduo e não no ambiente que o circunda. Teorias biológicas, entretanto, admitem que o meio ambiente possa exercer influência sobre as disposições orgânicas e hereditárias individuais.

Teorias biológicas da criminalidade sofrem, justificadamente, críticas e desconfiança quase generalizadas. Seus críticos recordam, 
por exemplo, que nelas "há uma forte tendência médica a distinguir entre 'são-enfermo' e 'normal-anormal', tornando diferente e enfermo aquele que delinque e pretendendo a normalidade de quem não o faz, noção que é substancialmente falsa", sem contar que, no plano político, "tem-se destacado o perigo que entranham as diferenças reais ou fictícias atribuídas a grupos humanos, ou especificamente a minorias" (ELBERT, 2009:105). Afirmam, igualmente, que seus dois principais pilares político-criminais - medida de segurança e medidas de tratamento - partem do pressuposto da existência de "personalidades defeituosas de índole biológico patológica" justificando, assim, com base em conclusões sobre anomalias cromossômicas, endócrinas e cerebrais medidas médicas como castração, alteração de sistemas glandulares e aniquilação de matéria cerebral por eletrochoque (MIRALLES, 1983:64-65).

Por outro lado, sustenta-se, na mesma linha de pensamento, mas com menos razão, que em decorrência da adoção do método positivista que fundamenta as investigações no pressuposto da "diferença", as teorias biológicas da criminalidade "tendem na interpretação de seus dados a exagerar as diferenças encontradas, distorcendo a realidade do mundo que observaram" e que, assim procedendo, elas exageram "a incidência do dado biológico no comportamento criminal” (MIRALLES, 1983:61). No passado, afirma-se, teorias biológicas da criminalidade defenderam a visão de que a explicação biológica seria a única verdadeiramente válida com exclusão de todas as demais, tendo formulado a tese caracteristicamente determinista de que o homem é um ser "vinculado a sua hereditariedade, escravo de seu passado, da carga biológica e genética que recebe e que faz do mesmo um produto terminado, um ser circunscrito em si mesmo e separado dos demais, mero objeto da história e incapaz de decidir por si e transformar a sociedade que lhe condiciona" (GARCIA-PABLOS, 1992:140). 
Neste estudo, pretende-se comprovar, contra a opinião corrente, que, mesmo no passado, teorias biológicas da criminalidade importantes relativizaram a influência do fator biológico no cometimento de crimes, muito embora isto não tenha sido suficiente para dissuadi-las de sugerir a adoção de políticas-criminais de natureza antiliberal com o fim de combater a delinquência. Com esta finalidade, foram selecionadas quatro obras de autores de diversas nacionalidades que produziram suas pesquisas no campo da biologia criminal. $\mathrm{O}$ estudo engloba pesquisadores das primeiras décadas do século passado aos anos sessenta. Naturalmente, não se pretende realizar aqui uma espécie de inventário acerca das teorias biológicas da criminalidade, mas revelar até que ponto elas caracterizaram-se pelo exclusivismo e determinismo, bem como em que medida propuseram medidas antiliberais de política criminal.

\section{O PROBLEMA DO UNILATERALISMO E A POLÍTICA CRIMINAL SUGERIDA PELA BIOLOGIA CRIMINAL ENTRE 1930 E 1960: O EXAME DO PENSAMENTO CRIMINOLÓGICO EM BIOLOGIA CRIMINAL.}

Dentre as subdisciplinas que integram a criminologia, a biologia criminal foi a que sofreu influência mais intensa do positivismo naturalista italiano. Sobretudo na primeira metade do século passado, estudiosos referiam-se ao criminoso como um ser humano biologicamente (e antropologicamente) diferente do indivíduo não criminoso em decorrência de fatores biológicos ou hereditários. Dentre estes cientistas, muitos acreditavam que a carga hereditária desfavorável inferiorizaria o primeiro diante dos segundos, considerados seres humanos normais (princípio da diferença, princípio da diversidade ou princípio do bem e do mal). Todas as pesquisas em biologia criminal pressupunham que a explicação do comportamento criminoso tinha por base uma patologia ou anormalidade individual. 
Este enfoque teórico, após ter experimentado uma fase de intenso prestígio, mergulhou em descrédito, sobretudo em consequência de ter servido para embasar políticas criminais autoritárias e totalitárias.

Em 1939, ano em que foi deflagrada a Segunda Guerra Mundial, publicou-se nos Estados Unidos uma extensa investigação criminológica iniciada em 1926. Pretendia-se descobrir se as características físicas dos indivíduos seriam relevantes em qualquer sentido para o cometimento de crimes. Ambicionando superar as deficiências da antropologia criminal da Escola Positiva italiana, a pesquisa buscava reexaminar os problemas que constituíram seu objeto de estudo e, ao mesmo tempo, superá-los com apoio na utilização de amostras numericamente adequadas, no isolamento dos tipos étnicos e raciais dos criminosos e no emprego correto da estatística, tudo isto utilizando o método da pesquisa de campo. No total, foram analisados 17.077 registros individuais, incluindo os registros de 3.203 não criminosos para efeito de comparação entre eles e os delinquentes (HOOTON, 1939:252-254).

Verificando a existência ou não de correlação entre os crimes individualmente cometidos e as características físicas dos criminosos, a pesquisa concluiu que, em comparação aos demais delinquentes, os homicidas de primeiro grau seriam, em sua maioria, mais velhos, mais encorpados, mais altos, possuindo maior diâmetro torácico, mandíbulas maiores e mais proporcionais à largura do rosto, ombros relativamente mais estreitos e tronco relativamente mais curto. Por sua vez, os homicidas de segundo grau tenderiam a serem ainda mais velhos, apresentando peito excessivamente profundo, cabeça não muito comprida e deficiências na largura do corpo e no peso. Já os assaltantes se distinguiriam dos demais pelo menos em dois dos trinta e nove caracteres métricos utilizados na investigação, não sendo antropologicamente diferentes dos demais, embora, admite o 
pesquisador, que isto pudesse ter sido checado caso a amostra tivesse sido ainda mais ampla. Por outro lado, os autores de furto discrepariam dos outros criminosos em cinco aspectos: idade abaixo da média, peito mais estreito e cabeça, rosto e nariz excessivamente compridos. Enfim, à semelhança dos positivistas italianos, a pesquisa correlacionava tipos físicos e tipos de ilícitos penais, concluindo que "os criminosos como um todo são morfologicamente diferentes de acordo com a natureza de seus crimes" (HOOTON, 1939:273).

Assim, após coligir uma infinidade de dados e conclusões parciais acerca da relação entre o crime e as condições sociais, psicológicas e, sobretudo, biológicas dos criminosos, concluiu-se o seguinte:

Nesta altura, podemos dizer que os resultados de nossa investigação não têm grande utilidade prática, ou seja, são poucas as conclusões que podem ser utilizadas pela polícia para prender criminosos: uma descrição precisa de um gângster típico não ajudará a prender Dillinger. Certas conclusões teóricas, no entanto, não são de pouca importância. Os criminosos são organicamente inferiores. O crime é resultante do impacto causado pelo meio ambiente sobre organismos humanos de baixa qualidade. Segue-se que a eliminação do crime pode ser efetuada apenas extirpando-se os fisicamente, mentalmente e moralmente inaptos ou segregando-os completamente em um ambiente socialmente asséptico (HOOTON, 1939:273). ${ }^{2}$

Percebe-se, assim, que a pesquisa assume integralmente, assim como outras investigações, o pressuposto teórico do princípio da inferioridade orgânica do indivíduo criminoso em relação ao não criminoso. Porém, contrariando o entendimento prevalecente de que elas se caracterizam pelo unilateralismo teórico determinista, pode-se observar que a pesquisa conclui que, embora os criminosos sejam

\footnotetext{
${ }^{2}$ Este e os demais grifos no texto são nossos.
} 
organicamente inferiores, a prática de crimes encontra-se condicionada ao impacto que o meio ambiente possa causar a tais "organismos humanos de baixa qualidade". Esta conclusão, porém, em nada afeta a proposta político criminal antiliberal do pesquisador que sugere a eliminação dos "fisicamente, mentalmente e moralmente inaptos" ou sua completa segregação em "um ambiente socialmente asséptico".

Também em fins dos anos trinta, um dos mais conhecidos nomes da biologia criminal alemã ofereceu uma obra de grande impacto para a criminologia do mundo ocidental a partir de uma visão integrada das ciências criminais (biologia criminal, ciência do direito penal e política criminal) na qual a primeira delas era concebida, de maneira ampla, como a intersecção da antropologia criminal (apoiada na hipótese fundamental do aspecto corporal do criminoso), da psicologia criminal (orientada aos estudos anímicos e processos espirituais do delinquente) e da sociologia criminal (que examina o delito como um fenômeno social e pretende investigar a condicionalidade do mundo circundante sobre o autor e o fato punível) (EXNER, 1946:34-35). Por conseguinte, o principal nome da biologia criminal alemã de sua época não adotava uma visão unilateral da criminalidade, tendo considerado a importância da psicologia e da sociologia na explicação dos comportamentos delituosos. Para ele, a biologia criminal (a criminologia) tinha por missão descrever e explicar as causas da criminalidade, considerada esta como um fenômeno social normal e necessário em todas as épocas e em todos os povos e, ao mesmo tempo, como um comportamento exclusivo de um maior ou menor grupo de pessoas em dada comunidade (EXNER, 1946:15-25). Neste aspecto, o autor combina curiosamente o positivismo característico da Escola Positiva italiana com a teoria estrutural-funcionalista da anomia de Durkheim. Ademais, em seu sentir, "o delito não é exclusivamente um 
processo natural", na medida em que necessita da "valoração da comunidade em que o criminoso vive" (EXNER, 1946:30). De toda sorte, para ele, três fatores contribuiriam para a formação da personalidade do indivíduo: fatores constitutivos pessoais (patrimônio hereditário), fatores conformadores pessoais (idade) e fatores formativos pessoais (mundo circundante).

Referindo-se aos fatores da criminalidade, o autor reconhece explicitamente que os fatores hereditários ainda seriam insuficientemente conhecidos, sendo inservíveis no sentido de basear conclusões definitivas no domínio da criminologia. Além disso, ele assinala, a formação da personalidade "também está determinada pelo mundo circundante, e o delito é sempre uma reação a impressões ambientais' (EXNER, 1946:205). Na esteira desta afirmação, o estudioso alemão rechaça veementemente o determinismo biológico e antropológico ao reconhecer que o criminoso não possui características hereditárias que o conduzem necessariamente ao crime, pois o que "há unicamente é um potencial hereditário que possivelmente evolui na mencionada direção, ou seja, não está demonstrado nem é demonstrável que um potencial hereditário conduza fatalmente ao desenvolvimento de propriedades que conduzam inevitavelmente ao delito" (EXNER, 1946:207). Em seu entendimento, o "mundo circundante" desempenha um "papel decisivo" juntamente com os fatores hereditários no que diz respeito ao comportamento criminoso (EXNER, 1946:357). Confirma-se, assim, a inexistência de uma visão unilateral e determinista do autor alemão em relação ao fenômeno da criminalidade.

Menos de duas décadas depois, mais precisamente em 1956, a biologia criminal americana, pretendendo trilhar caminhos distintos dos percorridos pelo positivismo naturalista italiano, relacionou uma vez mais as características psicológicas individuais e os fatores 
socioculturais aos tipos físicos, não obstante renegar a tese da antropologia criminal positivista peninsular de que o criminoso é um indivíduo hereditariamente degenerado.

De maneira bastante semelhante aos pioneiros da antropologia criminal, a investigação criminológica associou uma série de características físicas e psicológicas dos indivíduos aos diversos tipos de delitos (GLUECK; GLUECK, 1956). Porém, os pesquisadores concluem que o comportamento criminoso não pode ser explicado por um fator isoladamente considerado por entenderem ser necessário considerar as complexas relações entre os fatores hereditários e os ambientais, a exemplo daqueles que se referem às interações entre o indivíduo e seus familiares ou entre ele e a comunidade. Por outro lado, afirmam, também seria preciso levar em conta as motivações conscientes e inconscientes do criminoso. Em suma, os autores reconhecem que as teorias etiológicas da criminalidade não lograram identificar com precisão qual a profundidade e a extensão da influência recíproca entre os diversos fatores biológicos e o meio ambiente, uma vez que "a personalidade humana, o caráter e as motivações individuais estão longe de serem simples" (GLUECK; GLUECK, 1956:267-268). Contudo, ainda assim, eles professam sua esperança no desenvolvimento futuro de uma espécie de concepção causal realista que se esforce no sentido de "isolar as síndromes biossociais mais geralmente operativas nas vidas dos delinquentes e mais usualmente ausentes nas dos não delinquentes, o que não só contribuiria para a compreensão da relação entre causas e efeitos, mas destacaria as características, os fatores e as áreas mais relevantes tanto para o esforço terapêutico no caso individual quanto para o esforço profilático em geral" (GLUECK, GLUECK, 1956:269). Uma vez mais, portanto, a biologia criminal não deixou de considerar a importância de fatores ambientais na explicação do fenômeno criminal, afastando-se do 
unilateralismo e do determinismo. Também aqui pode-se notar traços da concepção terapêutica que historicamente encontra-se associada a este saber criminológico.

Por fim, na segunda metade do século passado, um dos principais nomes da criminologia italiana, mesmo defendendo o ponto de vista de que as causas individuais da criminalidade seriam mais importantes que as ambientais, admitiu explicitamente que "as pesquisas mais recentes e os mais modernos tratados de criminologia aceitam a prevalência da pluralidade de causas" (DI TULLIO, 1960:53). Em seu entendimento, "para uma compreensão mais exata das diversas manifestaçôes específicas do comportamento criminoso é necessário analisar as relaçôes intercambiáveis existentes entre o indivíduo e sua situação social no âmbito e no esquema da ordem social' (DI TULLIO, 1960:54). Consequentemente, afirma, "todo fenômeno criminal é sempre a expressão de um complexo de fatores causais, dentre os quais se encontram fatores individuais e fatores ambientais estreitamente conectados entre si", mesmo que o peso específico de cada um destes fatores possa variar conforme a situação concreta observada pelo pesquisador. $\mathrm{O}$ autor afirma que "existem delitos de natureza preponderantemente ambientais, como aqueles do tipo ocasional" e outros "de natureza predominantemente biológica, como os de tipo constitucional ou patológico". Seja como for, diz ele, "não existem fenômenos criminais derivados de um só grupo de fatores causais, na medida em que eles são sempre provocados por um complexo de fatores de natureza seja biológica, seja sociológica, que são pesquisados e avaliados caso a caso" (DI TULLIO, 1960:66).

De acordo com o estudioso italiano, estas relações intercambiáveis entre os diversos fatores da criminalidade seriam determinadas fundamentalmente pelos denominados "componentes de vulnerabilidade". Estes nada mais seriam que elementos da vida do 
indivíduo que o tornariam predisposto ao comportamento delituoso, classificando-se em internos (individuais) e externos (sociais). Os "componentes de vulnerabilidade" internos (irritabilidade, ansiedades, ausência de ideais, ansiedades, baixa tolerância às frustrações, dentre outros) interagiria com os externos (tensões e conflitos sociais, desestruturação familiar, ausência de controle social por instâncias mais amplas, etc.) contribuindo para a realização do crime. Em resumo, conclui o autor: "É somente o encontro das duas vulnerabilidades, pessoal e social, interna e externa, que pode originar um comportamento especificamente criminoso" (DI TULLIO, 1960:5455). Portanto, para o estudioso italiano, o enfoque sociológico contribui decisivamente para a explicação do fenômeno criminal ainda que seja secundário em relação ao biológico.

$\mathrm{Na}$ realidade, embora o autor admita a concorrência dos fatores biológicos, psicológicos e ambientais na causação da criminalidade - e reclame do unilateralismo dos sociólogos quando estudam as causas da delinquência -, ele sustenta que o meio ambiente se limita a influenciar os fatores internos que conduzem o indivíduo ao crime, modulando a frequência com que é cometido. Ele recorda que, na opinião dos pesquisadores no âmbito da biologia criminal, a causa principal do crime "é encontrada na personalidade individual que constitui o terreno sobre o qual atua o meio ambiente" (DI TULLIO, 1960:65). Concordando com estes últimos, o autor sustenta o ponto de vista de que mesmo sendo o indivíduo "a síntese de dois elementos que jamais podem ser dissociados”, na medida em que são interdependentes, "o ambiente não pode transformar totalmente as disposições individuais, razão pela qual a formação de um indivíduo vem a ser, em geral, estreitamente ligada ao modo como os caracteres hereditários reagem ao meio ambiente". Mesmo assim, conclui, a hereditariedade "não deve ser entendida como um destino 
imodificável, mas muito mais como uma força de orientação biopsicológica' que pode ser modificada pelo ambiente" (DI TULLIO, 1960:67).

A política criminal sugerida pelo pesquisador italiano baseia-se na denominada "profilaxia da criminalidade" que, por seu turno, fundamenta-se no conhecimento das causas e da dinâmica da delinquência individual e coletiva, destinando-se a "eliminar, ou ao menos limitar, todas as condições biológicas, psicológicas e sociais que, direta ou indiretamente favorecem o crime e a remover por um tempo mais ou menos longo da vida social, também com fins de reeducação, todo indivíduo perigoso do ponto de vista social ou criminal" (DI TULLIO, 1960:426). Trata-se, portanto, de uma proposta político criminal que se manifesta, à luz das doutrinas da pena, na prevenção especial positiva e negativa. Por outro lado, as medidas preventivas devem abranger praticamente todos os aspectos da vida social, concebida esta como a organização material e espiritual de cada família, a capacidade da escola de formar o caráter individual, a organização do trabalho capaz de satisfazer as necessidades da vida social, as instituições políticas e sociais organizadas sob critérios de justiça e de moralidade e a literatura e os meios de comunicação cujo funcionamento favoreça a moralidade individual e coletiva. Portanto, segundo o autor, a profilaxia da criminalidade deve ser concebida para atacar "todas as causas que podem causar dano ao desenvolvimento da personalidade humana e que possam, contudo, torná-la menos forte em relação às exigências da vida social e, especialmente, da moral codificada" (DI TULLIO, 1960:427).

No plano político criminal concreto, determinadas medidas sugeridas pelo autor italiano no que diz respeito ao combate das causas hereditárias (loucura, alcoolismo, sífilis, tuberculose) e das causas sociais (miséria, desocupação, ignorância) da criminalidade são 
manifestamente antiliberais, a exemplo de sua defesa de uma política criminal eugênica. Ele defende de maneira explícita o impedimento ou a limitação do matrimônio entre pessoas afetadas por psicopatias particularmente graves de natureza hereditária ou acometidas de formas graves de epilepsia, sífilis, alcoolismo e tuberculose, muito embora, em sentido contrário, se posicione contra a castração e a esterilização de "degenerados" e de "psicopatas" por entender que as causas das doenças hereditárias ainda eram pouco conhecidas. De maneira geral, o autor reconhece a carência de "base científica" suficiente capaz de justificar intervenções radicais na vida e no futuro dos indivíduos, tendo afirmado serem "muito numerosas as incertezas que persistem no campo da hereditariedade para que possamos ser capazes de formular juízos exatos e precisos sobre a idoneidade procriadora dos indivíduos" (DI TULLIO, 1960:429).

Na segunda metade do século passado a sociologia criminal tornouse o saber hegemônico no âmbito da criminologia diante do desprestígio experimentado pela biologia criminal. O fato é que determinadas conclusões desta disciplina revelaram-se antiéticas, como aconteceu, por exemplo, no campo das pesquisas genéticas. $\mathrm{Na}$ realidade, como assinala um estudioso do problema, "o reconhecimento de influências de natureza biológica e, mais concretamente, genética, parece chocar-se com determinados princípios e ideias que nos parecem básicos para nossa concepção moral do ser humano e da sociedade" (SERRANO MAÍLLO, 2003:54).

\section{O PERCURSO DA BIOLOGIA CRIMINAL NAS ÚLTIMAS DÉCADAS: BALANÇO CRÍTICO.}

Depois de ter sofrido um relativo desprestígio durante algumas décadas, a biologia criminal experimentou uma espécie de renascimento no final do século passado em consequência dos extraordinários avanços realizados sobretudo no campo da genética. 
Passou-se a admitir, com base em pesquisas mais aprofundadas, que fatores de natureza genética são importantes no que diz respeito à explicação de anomalias mentais, a exemplo da esquizofrenia, da psicose maníaco depressiva e, em geral, de determinadas patologias mentais. Embora enfrentem resistências, alguns pesquisadores advogam a tese de que a genética contribui igualmente para explicar a agressividade, o alcoolismo e mesmo a homossexualidade. Pesquisas criminológicas no campo da biologia criminal são desenvolvidas, por exemplo, a partir do estudo de indivíduos gêmeos ou adotados visando verificar se fatores genéticos e ambientais podem ou não interferir em seus comportamentos de modo a predispô-los ao cometimento de crimes (CID MOLINÉ; LARRAURI PIJOAN, 2001:69-70).

Por outro lado, enfoques biológicos mais radicais e unilaterais continuaram, com razão, a serem identificados com políticas criminais antiliberais e, consequentemente, atentatórias aos direitos humanos. Igualmente, não se pode negar que teorias biológicas da criminalidade tendem a justificar de maneira acrítica o funcionamento do sistema penal, resguardando a sua legitimidade (GARCÍA-PABLOS, 1982:139). Para alguns, inclusive, "até o dia de hoje não se tem podido demonstrar de modo conclusivo que exista uma diferença biológica essencial entre quem delinque e quem não o faz", considerando-se que "muitos indivíduos são portadores de traços típicos, mas não delinquem e viceversa" (ELBERT, 2009:104-105). Por último, autores afirmam, não inteiramente sem razão, que seja qual for a contribuição que a biologia criminal possa proporcionar ao estudo das causas da criminalidade, a política criminal resultante de suas pesquisas mesmo apontando, em maior ou menor medida, para a possibilidade de reintegração social do infrator, tende a privilegiar, em última análise, sobretudo em casos extremos, soluções direcionadas à prevenção especial negativa. Em suas exatas palavras: "A insistência nos fatores biológicos como causas 
da criminalidade deverá levar a dar prevalência, no plano da execução da pena, a fins de incapacitação do delinquente, pois não se depositará muita confiança na possibilidade de reabilitação" (CID MOLINÉ; LARRAURI PIJOAN, 2001:76).

Porém, não obstante as críticas enfrentadas pela biologia criminal contemporânea, autores reconhecem que as inúmeras insuficiências reveladas pela sociologia criminal têm contribuído sobremaneira para uma espécie de renascimento do enfoque biológico em criminologia (SERRANO MAÍLLO, 2003:54-56). De resto, não se pode deixar de admitir a evidência de que as últimas décadas do século assistiram a uma notável evolução do conhecimento no campo biológico, fenômeno que, reforçado pela renúncia da biologia criminal à pretensão exclusivista e unilateral no tocante à explicação da criminalidade, estimula a credibilidade na disciplina (FIGUEIREDO DIAS; COSTA ANDRADE, 1997:175). Por outro lado, admite-se que "as variáveis biológicas ou genéticas são geralmente compatíveis com as grandes e tradicionais construções teóricas da criminologia, como é o caso de teorias como a da aprendizagem, do controle social, o enfoque da rotulação ou as teorias da tensão". Em suma, a biologia criminal contemporânea favorece os enfoques integrados em criminologia, admitindo, de certa maneira, a importância da interdisciplinaridade (SERRANO MAÍLLO, 2003:83).

Em síntese, para muitos o ponto forte da biologia criminal continua a ser o elevado nível de empirismo presente em suas pesquisas, ao passo que seu aspecto mais criticável é a tendência a generalizar abusivamente as relações de causa e efeito a partir de um pequeno número de casos investigados. Apesar disso, mesmo seus críticos admitem, ao final e ao cabo, a relevância do fator biológico individual para a explicação do crime, reconhecendo que "não há dúvida de que o código biológico e genético é um dos componentes do contínuo e 
fecundo processo de interação, que é aberto e dinâmico e no qual se insere a conduta do homem" (GARCÍA-PABLOS, 1992:139).

Mesmo reconhecendo a impossibilidade anunciada desde a introdução a este estudo de que um balanço amplo e aprofundado dos problemas e virtudes da biologia criminal não pode ser feito neste momento, não se pode deixar de registrar que o enfoque biológico está presente atualmente no âmbito do conhecimento criminológico e tende a tornar-se mais e mais influente na medida em que o conhecimento experimental por ele produzido em laboratório aprofundar-se.

\section{CONCLUSÃO: DESFAZENDO UM EQUÍVOCO E REAFIRMANDO CERTEZAS.}

A esta altura, não se pode deixar de concluir, contrariando muitas vozes em sentido oposto, que mesmo durante as décadas de 30 a 60 do século passado, período em que a biologia criminal se revestiu de uma roupagem político criminal caracteristicamente antiliberal, pesquisadores importantes no âmbito da referida disciplina não adotaram um discurso unilateral exclusivista no que diz respeito às causas da criminalidade de maneira a afastar os fatores ambientais como relevantes para explicar o fenômeno criminal, como demonstrado por intermédio da análise de quatro grandes nomes da biologia criminal americana e europeia.

Por outro lado, confirma-se a partir da leitura de suas obras principais que os fundamentos da política criminal baseada nas teorias biológicas da criminalidade tenderam à formulação de propostas antiliberais e, consequentemente, contrárias aos direitos humanos. Evidentemente, tal conclusão não implica em reconhecer que a biologia criminal esteja impedida de avançar, embora talvez não completamente, na direção de propostas político criminais menos rigorosas do que as que foram examinadas neste estudo. Enfim, não se 
pode esquecer de que a política criminal não é nem deve ser inteiramente subordinada às conclusões científicas, incluindo as provenientes da biologia criminal. A política criminal possui uma dimensão eminentemente valorativa que não pode ser desprezada. Isto significa que, por mais cientificamente válidas que possam parecer determinadas conclusões provenientes da criminologia - incluindo a sociologia criminal - a política criminal construída pelo Estado democrático de direito há de considerar necessariamente princípios que o norteiam, a exemplo do valor dignidade da pessoa humana, dentre outros igualmente relevantes.

\section{REFERENCIAS}

CID MOLINÉ, J.; LARRAURI PIJOAN, E. Teorías criminológicas: explicación y prevención de la delincuencia. Barcelona: Bosch, 2001. DI TULLIO, B. Principi di criminologia clinica e psichiatria forense. Roma: Instituto di Medicina Sociale, 1960.

ELBERT, C. A. Novo manual básico de criminologia. Trad. Ney Fayet Júnior. Porto Alegre: Livraria do Advogado, 2009.

EXNER, F. Biología criminal. Barcelona: Bosch, 1946.

FIGUEIREDO DIAS, J. de; COSTA ANDRADE, M. da. Criminologia: o homem delinquente e a sociedade criminógena. Coimbra: Coimbra Editora, 1997.

GARCÍA-PABLOS DE MOLINA, A. Criminologia: uma introdução a seus fundamentos teóricos. São Paulo: Revista dos Tribunais, 1992. GLUECK, S.; GLUECK, E. Physique and delinquency. New York: Harper \& Brothers Publishers, 1956.

HOOTON, E. A. The American criminal: an anthropological study. Cambridge: Harvard University Press, 1939.

MIRALLES, T. Patología criminal: aspectos biológicos. In $\mathrm{R}$. BERGALLI, J. BUSTOS RAMÍREZ, T. MIRALLES. El pensamiento criminológico: un análisis crítico. Bogotá: Temis, 1983, v.1, p.51-67. 
SERRANO MAÍLLO, A. La posición de las variables biológicas en la criminología contemporánea. In ROMEO CASABONA, Carlos María (org.). Características biológicas, personalidad y delincuencia. Granada: Comares, 2003, p.49-93. 